\title{
The effect of knowledge of results upon contingent negative variation in a reaction time situation with a variable foreperiod
}

\author{
G. H. BLOWERS and G. C. ONGLEY \\ MRC Clinical Psy chiatry Unit, Graylingwell Hospital, Chichester, Sussex, England
}

\begin{abstract}
To examine the effects of knowledge of results $(\mathrm{KR})$ on the CNV, the vertex EEG was recorded during eight trials of each of five different foreperiods with ISIs of $1,3,5,7$, and 10 sec, in each of two conditions, with feedback by knowledge of results (KR) and without (no KR). Foreperiods were presented randomly from trial to trial to reduce the subject's anticipation of S2 onset, but median CNVs were computed in blocks of eight for each ISI. Results showed that peak amplitudes of the CNV increased with KR. Reaction times were shorter with KR than with no KR. However, correlations of peak CNV with reaction time were not significant. It is suggested that motivation by feedback of knowledge of results is a significant factor in CNV genesis.
\end{abstract}

The introduction of knowledge of results $(\mathrm{KR})$ to improve a subject's performance has been employed in foreperiod reaction time (RT) studies in conditions when foreperiod is fixed and when it is varied (e.g., Church \& Camp, 1965). These authors found that while fixed foreperiods produced shorter RTs than variable foreperiods, RT was faster in both paradigms when $\mathrm{KR}$ was introduced. Relevant to this study is contingent negative variation (CNV) which is a slow potential change of the EEG recorded from the fronto-vertical regions of the scalp. It is generated in situations where a stimulus to be responded to is preceded by a warning stimulus in a short time interval. While this paradigm has undergone many experimental manipulations in previous studies, few have involved the introduction of $\mathrm{KR}$, and these studies themselves have been conflicting. Peters, Knott, Miller, Van Veen, and Cohen (1970) showed that a response-terminated series of flashes produced shorter RTs and greater CNV amplitudes than a single flash. Otto (1971) showed an increase in CNV amplitudes when KR was introduced while Rebert (1972) confirmed Peters et al.'s finding for subjects judged to be making a genuine attempt to improve performance through the use of feedback, although at the same time he showed that explicit (i.e., numerical) feedback had no significant effect upon CNV amplitude compared with a no-feedback situation.

A common factor of the above-mentioned CNV studies is that they have employed only fixed foreperiods of short duration. It seems surprising that they did not extend their studies to include variable foreperiods of longer duration, considering that other studies have shown CNV to be generated over longer intervals (McAdam, Knott, and Rebert, 1969) both for

The present address of G. H. Blowers is: Department of Psychology, University of Hong Kong, Hong Kong. Please send all reprint orders to this address. situations in which foreperiods of the same value are grouped together and where foreperiods differing in value are quasirandomly presented (Blowers, Ongley, \& Shaw, 1973).

As foreperiods become longer, the course of the CNV becomes more variable and often the peak of the CNV amplitude occurs well short of the imperative stimulus. If CNV is a reflection of "preparatory set," as recent studies (e.g., Loveless, 1973) tend to confirm, then this result is to be expected since foreperiod variability tends to produce more uncertainty (i.e., longer RTs) in gauging the onset of the imperative stimulus (Botwinick \& Brinley, 1962; Karlin, 1959; Klemmer, 1956). Blowers, Ongley, and Shaw (1973) were able to demonstrate that for peak CNV amplitudes measured over a range of foreperiods, comparable values could be obtained in situations in which foreperiods were presented in groups of trials of the same foreperiod value and when foreperiods were quasirandomly presented. This means that when anticipation of the onset of $\mathrm{S} 2$ is reduced (as in the quasirandom sequence), CNVs of comparable amplitude are still generated.

As KR has been seen to decrease RT in fixed and variable foreperiod situations and (in some studies at least) increase CNV amplitude in fixed foreperiod situations, it would seem to be of interest to examine the effect of KR upon CNV-RT relationships in a variable foreperiod paradigm with the prediction that KR should increase CNV amplitude and decrease RT.

\section{VETHODS}

Fight female students, aged 18-21, were recruited as volunteers. All had taken part in a similar experiment (but without feedback), but none were aware of this experiment's purpose. The conditional or warning stimulus (S1) was a single auditory click, while the imperative stimulus (S2) was a $1,(000-\mathrm{Hz}$ tone lasting for a maximum of $600 \mathrm{msec}$, the subject 
Table 1

Means and Standard Deviations of "Standard" and "Peak" Amplitudes and Log Reaction Times as a Function of ISI

\begin{tabular}{|c|c|c|c|c|c|c|c|}
\hline \multirow[b]{2}{*}{ Variable } & \multirow{2}{*}{$\begin{array}{c}\text { Condi- } \\
\text { tion }\end{array}$} & \multirow[b]{2}{*}{ Statistic } & \multicolumn{5}{|c|}{ Interstimulus Interval (Seconds) } \\
\hline & & & 1 & 3 & 5 & 7 & 10 \\
\hline $\begin{array}{l}\text { "Standard" } \\
\text { Amplitude }\end{array}$ & A & $\begin{array}{l}\text { Mean } \\
\text { SD } \\
\text { Mean } \\
\text { SD }\end{array}$ & $\begin{array}{r}+.75 \\
7.40 \\
-8.25 \\
8.52\end{array}$ & $\begin{array}{l}0 \\
7.78 \\
-.25 \\
7.96\end{array}$ & $\begin{array}{r}+5.50 \\
10.18 \\
-.25 \\
5.39\end{array}$ & $\begin{array}{l}+2.0 \\
11.51 \\
+3.50 \\
12.73\end{array}$ & $\begin{array}{r}+8.0 \\
10.64 \\
+2.25 \\
7.59\end{array}$ \\
\hline $\begin{array}{l}\text { "Peak" } \\
\text { Amplitude }\end{array}$ & $\mathbf{A}$ & $\begin{array}{l}\text { Mean } \\
\text { SD } \\
\text { Mean } \\
\text { SD }\end{array}$ & $\begin{array}{r}+.75 \\
7.40 \\
-8.25 \\
8.52\end{array}$ & $\begin{array}{r}-5.75 \\
7.05 \\
-9.75 \\
7.52\end{array}$ & $\begin{array}{c}-5.50 \\
10.40 \\
-11.0 \\
3.85\end{array}$ & $\begin{array}{r}-5.25 \\
8.0 \\
-10.75 \\
6.32\end{array}$ & $\begin{array}{r}-8.50 \\
10.41 \\
-14.25 \\
6.96\end{array}$ \\
\hline $\begin{array}{l}\text { Log } \\
\text { Reaction } \\
\text { Time }\end{array}$ & B & $\begin{array}{l}\text { Mean } \\
\text { SD } \\
\text { Mean } \\
\text { SD }\end{array}$ & $\begin{array}{r}2.488 \\
.064 \\
2.474 \\
.035\end{array}$ & $\begin{array}{r}2.532 \\
.059 \\
2.463 \\
.032\end{array}$ & $\begin{array}{r}2.542 \\
.053 \\
2.459 \\
.022\end{array}$ & $\begin{array}{r}2.565 \\
.079 \\
2.475 \\
.051\end{array}$ & $\begin{array}{r}2.579 \\
.104 \\
2.488 \\
.050\end{array}$ \\
\hline
\end{tabular}

Note $-A=$ nonfeedback $($ no $K R)$ condition, $B=$ feedback $(K R)$ condition. $N=8$.

responding by pressing a key that terminated $\mathrm{S} 2$.

The presentation of stimuli within trials was controlled by a DEC PDP-12 computer which also computed signal medians. The signals used were derived from a vertex electrode $(\mathrm{Cz})$ referred to the slider of a potentiometer connected between a frontal pole electrode and paired mastoid electrodes to balance out ocular potentials (McCallum and Walter, 1968). 1 With collodion, dc stick-on electrodes (Chambers Instruments) were attached to the scalp.

The signals were recorded using ac amplifiers with a time constant of $6 \mathrm{sec}$ and a high-frequency $3-\mathrm{dB}$ turnover value of $35 \mathrm{~Hz}$.

An 11-sec epoch of EEG signal starting .4 sec before S1 was digitized and stored on magnetic tape on the PDP-12 computer. The .4 sec preceding $S 1$ was used to establish a dc baseline. The sampling rate was 45.5 samples per second, and this resulted in a sampling interval of $21.5 \mathrm{msec}$.

After the electrodes were fixed, subjects were seated in an easy chair, and eye potentials were balanced out. Eyes were shut throughout the experiment. A familiarization series of 16 clicks followed by eight click-tone pairs was presented to reduce effects due to stimulus novelty, sequence presentation, and to enable the subjects to associate the stimuli in pairs. Subjects were then told to press the key "as fast as you can to the tone, using the click as a warning," and were then presented with eight familiarization trials of ISI $1 \mathrm{sec}$. There then followed 40 trials (requiring response) made up of five interstimulus intervals of values $1.0,3.0,5.0,7.0$, and $10.0 \mathrm{sec}$, with eight trials per interval, and with ISI values occurring in random order. This sequence of 40 provided the data for the control or no KR condition of the experiment. The PDP- 12 computer was programmed to measure RT for each trial of this sequence and at the end calculate and store its mean value. A second (different) sequence of 40 trials was then presented. The computer was programmed to indicate to the experimenter after each of these trials whether or not RT for that trial was shorter than the mean of that found during the previous sequence. No information about the numerical value of $\mathrm{RT}$ was relayed to the experimenter at this time. Subjects were informed in the interval between the two halves of the experiment that their mean RT in the first half of the experiment had been calculated and that they would for the remainder of the paradigm be required to improve their keypress performance. They were informed of the results of each trial by the words "hit," on beating the mean, and "miss," on failure to do so. This sequence provided the feedback (KR) condition of the experiment. Intertrial intervals of between 2 and $15 \mathrm{sec}$ were varied randomly by the experimenter. Trials in which artifacts (i.e., noise or unnecessary movements by the subject causing spurious pen deflections) or keypressing in advance of the onset of the imperative stimulus occurred, were rejected. Each rejected foreperiod was added to the end of the sequence and presented again to the subject. 2

Using appropriate PDP-12 computer programs, the signals were averaged in groups of eight of the same ISI value and the median values stored in digital form on magnetic tape. The median has been reported as a more suitable measure for improving signal to noise ratio when artifacts are present in occasional trials (Borda \& Frost, 1968).

Two measures of the median signals were used to test the hypothesis. These were: (1) the "standard" amplitude, that is, the mean amplitude for 172-msec (i.e., eight consecutive sample points equal to eight times the sampling interval of $21.5 \mathrm{msec}$ ) period occurring immediately prior to $\mathrm{S} 2$; (2) the "peak" amplitude, that is, the mean of the eight consecutive sample points representing the highest amplitude between the stimuli, the first point (and highest value) of which is selected manually, using a display and cursor program. Results using these measures in a similar paradigm have been discussed elsewhere (Blowers, Ongley, \& Shaw, 1973).

\section{RESULTS}

The means and standard deviations of the waveform measures and reaction times as a function of ISI are shown in Table 1.

An example of a median waveform for one subject (eight trials), together with the corresponding averaged EOG, is shown in Figure 1 for both conditions of feedback (KR) and no feedback (no KR) with a foreperiod equal to $3 \mathrm{sec}$. It can be seen that the "standard" amplitude is smaller than the "peak" amplitude in each condition, and also the "peak" amplitude is larger for the feedback condition.

The statistical model for this experiment is a three-factor mixedeffects model (Scheffé, 1959; Snedecor \& Cochran, 1971) of Conditions by Intervals by Subjects. Interaction terms were found to be nonsignificant for all measures and were pooled into the residual terms for further calculation of the $F$ values of the main terms (Winer, 1962).

The application of the "standard" amplitude measures 


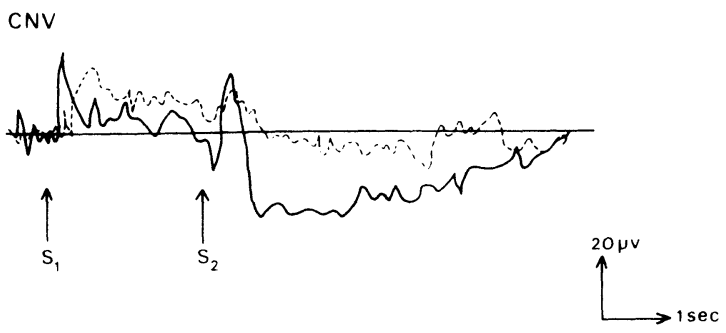

EOG
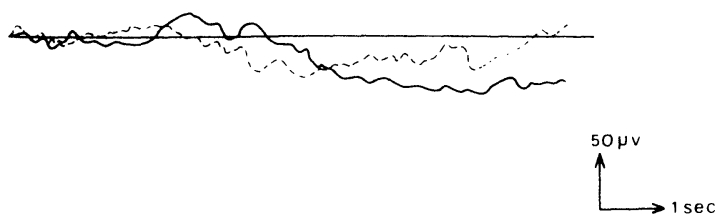

Figure 1. Example of one subject's median waveform of 10 CNV trials together with corresponding EOG. ISI = 3 sec. Solid lines = condition of no feedback (no KR). Dashed lines = condition of feedback (KR).

to the statistical model showed no significant differences between either conditions or intervals. The "peak" amplitude data, on the other hand, showed a significant effect for conditions-"peak" amplitude was greater when subjects were receiving feedback $(F=7.60$, $\mathrm{p}=.05, \mathrm{df}=1 / 11)$. "Peak" amplitude also showed a significant difference between intervals $(F=3.40$, $\mathrm{p}=.05, \mathrm{df}=4 / 32)$. On applying Guilford's modification of Tukey's test (Guilford, 1965,p. 277) to the means of the "peak" amplitudes over subjects as a function of ISI, it was found that the 1-sec ISI was significantly lower and the 10-sec ISI significantly higher than the population mean of "peak" amplitudes over all intervals. Figure 2 shows a graph of the "peak" amplitude measures averaged over subjects for each condition. The standard deviation values are shown in Table 1.

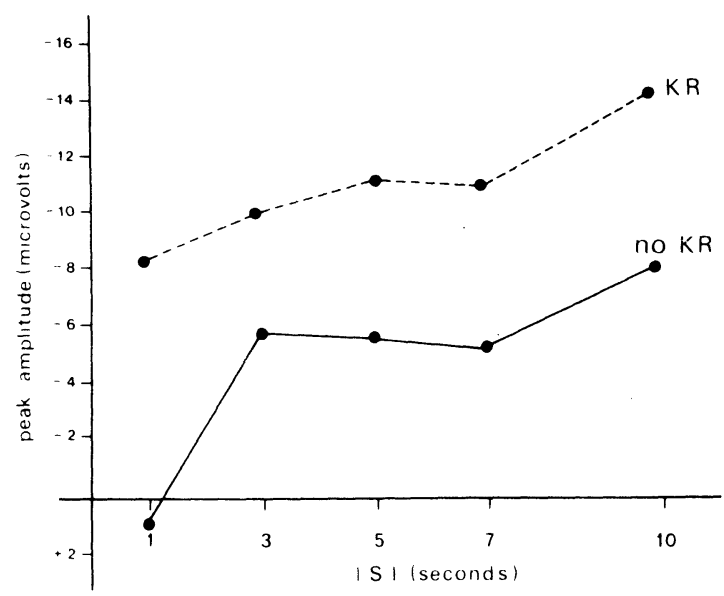

Figure 2. Graph showing mean peak amplitude for eight subjects as a function of feedback (KR) vs. no feedback (no KR) and ISI value.
The mean log reaction time scores, plotted against interstimulus interval for two conditions are shown in Figure 3.

Figure 3 shows that, in the no feedback condition, there is an increase in mean reaction time (RT) as interval is lengthened. In the feedback condition, mean RTs are much shorter and are less dependent upon interval. When the RT measures were applied to the model, they showed significant differences between conditions $(\mathrm{F}=14.12, \mathrm{p}=.01, \mathrm{df}=1$ and 11$)$, and between intervals $(F=4.11, p=.01, \mathrm{df}=4$ and 32$)$, the significant intervals being 1 and 10 sec.

From the mean values at each ISI for each subject, Spearman rho correlations were computed within intervals between "peak" amplitude and log reaction time for both KR and no-KR conditons. None of the

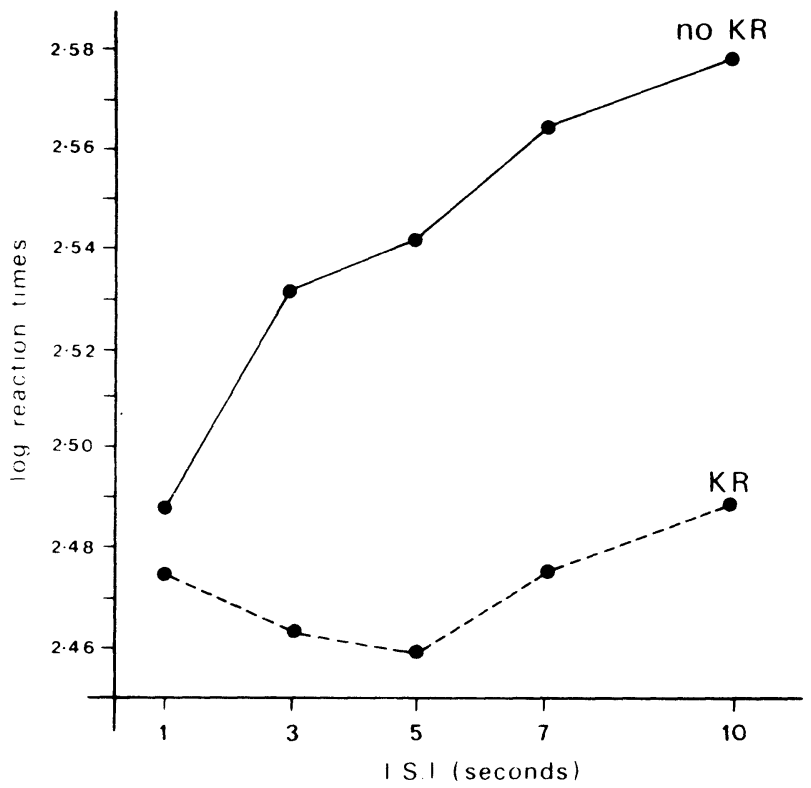

Figure 3. Graph showing mean $\log$ reaction times for eight subjects as a function of feedback (KR) vs. no feedback (no KR) and ISI value.

correlations proved significant. Within subjects correlations between log reaction time and ISI proved significant ( $p=.05$ or better) for four of the eight subjects in the no-KR condition, although the trend in all subjects was for larger RTs as ISI increased. None of the within subject correlations in the KR condition reached significance.

\section{DISCUSSION}

As predicted, the results show that feedback by knowledge of results (KR) led to significantly greater "peak" CNV amplitudes and significantly lower RT scores than no feedback. "Standard" amplitudes were very low throughout and not significantly different in 
the two conditions.3 Reaction time scores are in agreement with the literature cited for RT studies as well as with the findings of the CNV study of McAdam, Knott, and Rebert (1969). For the no-KR or control condition, RT became longer as foreperiod increased. The presence of KR was seen to produce greater "peak" CNV amplitudes and shorter RTs and may therefore be regarded as motivating. Subjects reported being more interested in the $\mathrm{KR}$ part of the experiment.

The motivating effects of $\mathrm{KR}$ would seem to be a suitable explanation of the changes in CNV amplitude which was the conclusion of Otto (1971). While Rebert (1972) has since challenged this conclusion, arguing that the difficulty of obtaining feedback, and not feedback per se, is a potent factor in CNV formation, he has subsequently failed to confirm this (Rebert \& Sperry, 1973).

It seems, therefore, that motivation through "feedback in action" (Annett, 1969) is a variable in CNV formation. The present study, like that of Otto (1971) employed KR as a means of giving feedback to subjects, and this resulted in larger "peak" CNVs and shorter RTs. This result occurred in a variable foreperiod paradigm over a range of long foreperiods where subjects' anticipation of the onset of the imperative stimulus was reduced. Motivation, by knowledge of results, is thus thought to be a major factor in $\mathrm{CNV}$ genesis.

\section{REFERENCES}

Annett, J. Feedback and human behaviour. Harmondsworth: Penguin Books. 1969.

Blowers, G. H., Ongley, G. C., \& Shaw, J. C. The effect of reducing temporal expectancy on the Contingent Negative Variation. Electroencephalography and Clinical Neurophysiology, 1973, 34, 259-264.

Borda, R. P., \& Frost, J. D. Error reduction in small sample averaging through the use of the median rather than the mean. Electroencephalography and Clinical Neurophysiology, 1968, 25, 391-392.

Botwinick, J., \& Brinley, J. F. An analy sis of set in relation to reaction time. Journal of Experimental Psychology, 1962, 63, 568-574.

Church, R. M., \& Camp, D. S. Change in reaction time as a function of knowledge of results. American Journal of Psychology, 1965, 78, 102-106.

Corby, J. C., \& Kopell, B. S. Differential contributions of blinks and vertical eye movements as artifacts in EEG recording. Psy chophysiology, 1972, 9, 640-644.

Girton, D. G., \& Kamiya, J. A simple on-line technique for removing eye movement artifacts from the EEG Electroencephalography and Clinical Neurophysiology, 1973 , 34, 212-216.

Guilford, J. P. Significant deviations of set means from a population mean. In: Fundamental statistics in psychology and education. New York: McGraw-Hill, 1965. Pp. 277-278.
Karlin, L. Reaction time as a function of foreperiod duration and variability. Journal of Experimental Psychology, 1959, 58, 185-191.

Klemmer, E. T. Time uncertainty in simple reaction time. Joumal of Experimental Psy chology, 1956, 51, 179-184.

Loveless, N. E. The Contingent Negative Variation related to preparatory set in a reaction time situation with variable foreperiod. Electroencephalography and Clinical Neurophysiology, 1973, 35, 369-374.

McAdam, D. W., Knott, J. R., \& Rebert, C. S. Cortical slow potential changes in man related to interstimulus interval and to pre-trial prediction of interstimulus interva. Psy chophysiology, 1969, 5, 349-359.

McCallum, W. C., \& Walter, W. G. The effects of attention and distraction on the contingent negative variation in normal and neurotic subjects. Electroencephalography and Clinical Neuro ph y siology, $1968,25,319-329$.

Otto, D. A. The effect of modifying response and performance feedback parameters on the CNV in humans. Paper presented at the Second International CNV Congress. Vancouver, B. C. Canada. June 1971 .

Peters, J. F., Knott, J. R., Millex, L. H., Van Veen, W. J., \& Cohen, S. I. Response variables and magnitude of the CNV. Electroencephalography and Clinical Neurophysiology, 1970 , $29,608-611$.

Rebert, C. S. The effect of reaction time feedback on reaction time and contingent negative variation. Psychophysiology, $1972,9,334-339$.

Rebert, C. S., \& Sperry, K. G. Subjective and response-related determinants of CNV amplitude. Psychophysiology, 1973, 10, 139-144.

Scheffe, H. The analysis of variance. New York: Wiley, 1959. Pp. 282-289.

Snedecor, G. W., \& Cochran, W. G. Statistical methods. Iowa State University Press, 1971. Pp. 346-369.

Weerts, T. C., \& Lang, P. J. The effects of eye fixation and stimulus and response location on the Contingent Negative Variation (CNV). Biological Psychology, 1973, 1, 1-19.

Winer, B. J. Statistical principles in experimental design. New York: McGraw-Hill, 1962. P. 205.

\section{NOTES}

1. This method has been criticized in recent reports (Corby \& Kopell, 1972; Girton \& Kamiy a, 1973; Weerts \& Lang, 1973) primarily because the relationship of eye movement artifact to CNV may not be constant, and eyeblink and eye movement potentials do not propogate over the head at the same diminishing rate. The use of this technique in the present study is defended on the grounds that (1) eye blink potentials were cancelled out from the vertex leads prior to each experimental run; (2) subjects performed the experiment with eyes closed, thus reducing large eye movements; (3) a product-moment correlation of both "peak" and "standard" CNV amplitudes with curresponding points of the EOG failed to reach significance.

2. The signal for accept/reject was relayed to the computer prior to the signal returning from computer to the experimenter informing him of whether the subject had "hit" or "miss." In this way, biassing of results through the experimenter having knowledge of the subject's performance was avoided.

3. A possible criticism of the experiment is the use of a 6 -sec time constant for relatively long foreperiods. This is justified on the basis that the same parameters obtained in two different conditions were compared. In addition, dc records were obtained concurrently on another channel, and they gave similar results but are not included because of problems of occasional drift.

(Received for publication August 13, 1974; revision accepted January 30,1975 .) 